Article

\title{
Synthesis, Crystal Structures, Optical Properties and Theoretical Calculations of Two Metal Chalcogenides $\mathrm{Ba}_{2} \mathrm{AlSbS}_{5}$ and $\mathrm{Ba}_{2} \mathrm{GaBiSe}_{5}$
}

\author{
Xiaowen $\mathrm{Wu}^{1}$, Xiaofeng $\mathrm{Gu}^{1}{ }^{1}$, Hui Pan ${ }^{1}$, $\mathrm{Yi} \mathrm{Hu}^{1}$ and $\mathrm{Kui} \mathrm{Wu}^{2, *}$ \\ 1 College of Chemistry and Chemical Engineering, Xinjiang Normal University, Urumqi 830017, China; \\ wuxiaowen1114@163.com (X.W.); xiaofenglively@126.com (X.G.); panhui86@163.com (H.P.); \\ breaker1001@sina.com (Y.H.) \\ 2 Xinjiang Technical Institute of Physics \& Chemistry of CAS, Urumqi 830011, China \\ * Correspondence: wukui@ms.xjb.ac.cn
}

Received: 19 March 2018; Accepted: 9 April 2018; Published: 13 April 2018

\begin{abstract}
Two quaternary metal chalcogenides, $\mathrm{Ba}_{2} \mathrm{AlSbS}_{5}$ and $\mathrm{Ba}_{2} \mathrm{GaBiSe}_{5}$, were successfully synthesized by solid-state reaction in sealed silica tubes. Both of them crystallize in the same orthorhombic space group Pnma, but they appear with obviously different construction features. For example, $\mathrm{Ba}_{2} \mathrm{AlSbS}_{5}$ exhibits $\left[\mathrm{SbS}_{3}\right]^{3-}$ units and zero-dimensional (0D) $\left[\mathrm{AlSbS}_{5}\right]^{4-}$ clusters, which is different from those $\left(\left[\mathrm{BiSe}_{6}\right]^{3-}\right.$ units and $1 \mathrm{D}_{\infty}\left[\mathrm{GaBiSe}_{5}\right]^{4-}$ chains) of $\mathrm{Ba}_{2} \mathrm{GaBiSe}_{5}$. We also systematically investigated the entire series of $\mathrm{Ba}_{2} \mathrm{M}^{\mathrm{III}} \mathrm{M}^{\mathrm{III}} \mathrm{Q}_{5}\left(\mathrm{M}^{\mathrm{III}}=\mathrm{Al}, \mathrm{Ga}\right.$, In; $\mathrm{M}^{\mathrm{III}}=\mathrm{As}, \mathrm{Sb}, \mathrm{Bi}$; $\mathrm{Q}=\mathrm{S}, \mathrm{Se}, \mathrm{Te}$ ) compounds, and the results showed that the interconnection of $\mathrm{M}^{\mathrm{III}} \mathrm{Q}_{4}$ and $\mathrm{M}^{\mathrm{III}} \mathrm{Q}_{n}$ $(n=3,5,6)$ units can form three different structural types, including $0 \mathrm{D}\left[\mathrm{M}^{\mathrm{III}} \mathrm{M}^{\mathrm{III}} \mathrm{Q}_{5}\right]$ clusters, single $\left[\mathrm{M}^{\mathrm{III}} \mathrm{Q}_{3}\right]$ chains and isolated $\left[\mathrm{M}^{\mathrm{III}} \mathrm{Q}_{4}\right]$ units, or $\left[\mathrm{M}^{\mathrm{III}} \mathrm{Q}_{3}\right]_{n}$ and $\left[\mathrm{M}^{\mathrm{III}} \mathrm{Q}_{3}\right]_{n}$ double chains, which may be induced by the flexible coordination and on-link modes of $\mathrm{M}^{\mathrm{III}}$ atoms. Spectral investigation shows that their bandgaps are about $2.57 \mathrm{eV}$ for $\mathrm{Ba}_{2} \mathrm{AlSbS}_{5}$ and $2.14 \mathrm{eV}$ for $\mathrm{Ba}_{2} \mathrm{GaBiSe}_{5}$. Theoretical calculation was also used to analyze their structure-property relationships, and the results indicate that the title compounds exhibit larger birefringences $(\Delta n>0.10)$, thus having potential as the IR birefringent materials.
\end{abstract}

Keywords: metal chalcogenides; crystal structure; theoretical calculation

\section{Introduction}

Metal chalcogenides have been used as critical materials in the development of modern science and technology because of their structural complexities and fascinating properties [1-12]. Among them, many trivalent cations (such as $\mathrm{M}^{\mathrm{III}}$ : $\mathrm{As}, \mathrm{Sb}$, or $\mathrm{Bi}$ ) containing chalcogenides have been discovered and shown to have various application prospects. With stereochemically active lone-pair electrons, the above trivalent cations exhibit a flexible coordination environment for the formation of $\mathrm{M}^{\mathrm{III}} \mathrm{Q}_{n}$ units ( $n=3 \sim 6 ; \mathrm{Q}=$ chalcogen), which offers an opportunity to affect their crystal structures and physicochemical properties [13-24]. For example, $\mathrm{AAs}_{2}(\mathrm{~A}=\mathrm{Li}, \mathrm{Na} ; \mathrm{Q}=\mathrm{S}, \mathrm{Se})$ [15] and $\mathrm{A}_{3} \mathrm{Ta}_{2} \mathrm{AsS}_{11}(\mathrm{~A}=\mathrm{K}, \mathrm{Rb})[13]$ compounds feature $\left[\mathrm{AsS}_{3}\right]^{3-}$ pyramids and show strong second harmonic generation (SHG) responses; $\mathrm{BaBiTe}_{3}, \mathrm{AgBi}_{3} \mathrm{~S}_{5}$ and $\mathrm{A}_{2} \mathrm{Bi}_{8} \mathrm{Se}_{13}(\mathrm{~A}=\mathrm{Rb}, \mathrm{Cs})$ compounds exhibit small bandgaps and have promising potential as thermoelectric materials [22-24]; $\mathrm{Ba}_{2} \mathrm{GaAsSe}_{5}$ shows novel $\left[\mathrm{AsGaSe}_{5}\right]^{4-}$ anions and high visible-light-induced photocatalytic reactivity [17]. In addition, overall literature research indicates that the above $\mathrm{M}^{\mathrm{III}} \mathrm{Q}_{n}$ units can bridge other functional units to form a variety of extended structures [16]. Moreover, Ba atoms have flexible coordination numbers (6 to 10) with chalcogens, owing to their large ionic radii, which can also produce distinctive structures in combination with $\mathrm{M}^{\mathrm{III}} \mathrm{Q}_{n}$ units. So far, many efforts have been focused on the Ba-M $\mathrm{M}^{\mathrm{III}-} \mathrm{M}^{\mathrm{III}}-\mathrm{Q}$ system, 
and several compounds with the $\mathrm{Ba}_{2} \mathrm{M}^{\mathrm{IIII}} \mathrm{M}^{\mathrm{III}} \mathrm{Q}_{5}\left(\mathrm{M}^{\mathrm{III}}=\mathrm{Ga}\right.$, In) formula have been discovered [17-21]. Unfortunately, their structural changes and theoretical calculations have not been systematically studied. Herein, we have focused our attentions on the $\left(\mathrm{M}^{\mathrm{III}}=\mathrm{Al}, \mathrm{Ga} ; \mathrm{M}^{\mathrm{III}}=\mathrm{Sb}, \mathrm{Bi}\right)$ system and two metal chalcogenides, $\mathrm{Ba}_{2} \mathrm{AlSbS}_{5}$ and $\mathrm{Ba}_{2} \mathrm{GaBiSe}_{5}$, were successfully synthesized. Note that $\mathrm{Ba}_{2} \mathrm{AlSbS}_{5}$ was the first discovered compound in the Ba-Al-Sb-S system. We have also systematically investigated the structural changes in the series of $\mathrm{Ba}_{2} \mathrm{M}^{\mathrm{III}} \mathrm{M}^{\mathrm{III} \prime} \mathrm{Q}_{5}\left(\mathrm{M}^{\mathrm{III}}=\mathrm{Al}, \mathrm{Ga}, \mathrm{In} ; \mathrm{M}^{\mathrm{III} \prime}=\mathrm{As}, \mathrm{Sb}, \mathrm{Bi} ; \mathrm{Q}=\mathrm{S}, \mathrm{Se}, \mathrm{Te}\right)$ compounds and analyzed the effect of interconnection between $\mathrm{M}^{\mathrm{III}} \mathrm{S}_{4}$ and $\mathrm{M}^{\mathrm{III}} \mathrm{S}_{n}$ units. Theoretical calculations were used to analyze their structure-property relationships.

\section{Materials and Methods}

\subsection{Synthesis}

The raw materials, including the Ba block (99.9\%), Al slice (99.99\%), Ga block (99.9\%), Sb block (99.99\%), Bi powder $(99.99 \%)$, S powder $(99.99 \%)$ and Se powder $(99.99 \%)$, were purchased from Shanghai Aladdin Biochemistry Technology Co., Ltd. (Shanghai, China). All preparations were completed in a glovebox with Ar atmosphere. Raw materials with stoichiometric proportion were loaded into the silica ampoules with diameter $10 \mathrm{~mm}$ and length $100 \mathrm{~mm}$, evacuated under high-vacuum $\left(10^{-3} \mathrm{~Pa}\right)$, and flame-sealed.

\subsection{1. $\mathrm{Ba}_{2} \mathrm{AlSbS}_{5}$}

The raw mixture with $2 \mathrm{mmol} \mathrm{Ba}, 1 \mathrm{mmol} \mathrm{Al}, 1 \mathrm{mmol} \mathrm{Sb}$ and $5 \mathrm{mmol} \mathrm{S}$ powders were loaded into the silica ampoules, sealed under vacuum, and then placed into the muffle furnace to complete the solid-state reaction. The temperature control curve was set as following: firstly, it was heated to $1273 \mathrm{~K}$ over $30 \mathrm{~h}$ (kept at this temperature for $50 \mathrm{~h}$ ), cooled to $673 \mathrm{~K}$ at a rate of $3 \mathrm{~K} / \mathrm{h}$, and finally cooled to room temperature by switching off the furnace. $N, N$-dimethylformamide (DMF) was used to remove the other impurity phases in an ultrasonic cleaner. Many yellow $\mathrm{Ba}_{2} \mathrm{AlSbS}_{5}$ crystals were finally discovered, and were stable for several months.

\subsection{2. $\mathrm{Ba}_{2} \mathrm{GaBiSe}_{5}$}

The preparation process of $\mathrm{Ba}_{2} \mathrm{GaBiSe}_{5}$ is similar to that of $\mathrm{Ba}_{2} \mathrm{AlSbS}_{5}$. The raw mixture with stoichiometric ratio was loaded into the silica ampoule, evacuated, flame-sealed and then placed into the muffle furnace for heating. The temperature control curve was set as following: firstly, it was heated to $1173 \mathrm{~K}$ over $30 \mathrm{~h}$, then left at this temperature about $100 \mathrm{~h}$, cooled to $573 \mathrm{~K}$ at a rate of $5 \mathrm{~K} / \mathrm{h}$, and finally cooled to room temperature by switching off the furnace. $\mathrm{Red}^{\mathrm{Ba}} \mathrm{GaBiSe}_{5}$ crystals were found after repeatedly washing with DMF solvent, and these were also stable in air.

\subsection{Structure Determination}

Selected single-crystals were used for data collection with a Bruker SMART APEX II 4K CCD diffractometer (Bruker Corporation, Madison, WI, USA) using Mo K $\alpha$ radiation $(\lambda=0.71073 \AA$ ) at room temperature. The multi-scan method was used for absorption correction [25]. All the crystal structures were solved by the direct method and refined using the SHELXTL program package (Shelxtl 1997) [26]. The final structures were carefully checked with the PLATON software (Glasgow, UK), and no other symmetries were found. We measured the element contents in the title compounds with an EDX-equipped Hitachi S-4800 SEM (Tokyo, Japan). The measurement results for single crystals of $\mathrm{Ba}_{2} \mathrm{AlSbS}_{5}$ confirmed the $\mathrm{Ba} / \mathrm{Al} / \mathrm{Sb} / \mathrm{S}$ molar ratio of 2.14:1:0.92:4.90, which was in good agreement with the stoichiometric proportions from single-crystal X-ray structural analysis. Similarly, the EDS elemental analysis of single crystals of $\mathrm{Ba}_{2} \mathrm{GaBiSe}_{5}$ confirmed the $\mathrm{Ba} / \mathrm{Ga} / \mathrm{Bi} / \mathrm{Se}$ molar ratio of 1.93:1.15:1.09:4.81, which is also in good agreement with the stoichiometric proportions. Table 1 shows the crystal data and structure refinement of the title compounds. 
Table 1. Crystal data and structure refinement for the title compounds.

\begin{tabular}{ccc}
\hline Empirical Formula & Ba $_{\mathbf{2}} \mathbf{A l S b S}_{\mathbf{5}}$ & Ba $_{\mathbf{2}} \mathbf{G a B i S e}_{5}$ \\
\hline $\mathrm{fw}$ & 583.71 & 948.18 \\
crystal system & orthorhombic & orthorhombic \\
space group & Pnma & Pnma \\
$a(\AA)$ & $12.140(3)$ & $12.691(4)$ \\
$b(\AA)$ & $8.8911(17)$ & $9.190(3)$ \\
$c(\AA)$ & $8.9552(17)$ & $9.245(3)$ \\
$\mathrm{Z}, V\left(\AA^{3}\right)$ & $4,966.6(4)$ & $4,1078.2(6)$ \\
$\mathrm{D}_{c}\left(\mathrm{~g} / \mathrm{cm}^{3}\right)$ & 4.011 & 5.841 \\
$\mu\left(\mathrm{mm}^{-1}\right)$ & 11.922 & 42.757 \\
$\mathrm{GOF}$ on F & 1.080 & 0.997 \\
$R_{1}, w R_{2}(\mathrm{I}>2 \sigma(\mathrm{I}))^{\text {a }}$ & $0.0202,0.0473$ & $0.0273,0.0499$ \\
$R_{1}, w R_{2}($ all data $)$ & $0.0225,0.0485$ & $0.0371,0.0535$ \\
largest diff. peak and hole $\left(\mathrm{e} \AA^{-3}\right)$ & $1.351,-0.780$ & $1.570,-1.648$ \\
\hline${ }^{\mathrm{a}} R_{1}=F_{\mathrm{o}}-F_{\mathrm{c}} / F_{\mathrm{o}}$ and $w R_{2}=\left[w\left(F_{\mathrm{o}}{ }^{2}-F_{\mathrm{c}}{ }^{2}\right)^{2} / w F_{\mathrm{o}}{ }^{4}\right]^{1 / 2}$ for $F_{\mathrm{o}}{ }^{2}>2 \sigma\left(F_{\mathrm{o}}{ }^{2}\right)$.
\end{tabular}

\subsection{Powder XRD Measurement}

A Bruker D2 X-ray diffractometer (Madison, WI, USA) with Cu K $\alpha$ radiation $(\lambda=1.5418 \AA)$ was used to measure the powder X-ray diffraction (XRD) patterns of the title compounds at room temperature. The measured range was 2 theta $=10-70^{\circ}$ with a step size of $0.02^{\circ}$. Note that the calculated XRD patterns were derived from the respective single-crystal data. We carefully investigated the experimental XRD patterns of the title compounds and compared the extra peaks with those of other known related compounds. As for the impurity peaks, several small peaks can be attributed to the $\mathrm{XRD}$ peaks of $\mathrm{BaSb}_{2} \mathrm{~S}_{4}$ and $\mathrm{BaGa}_{2} \mathrm{Se}_{4}$, respectively (Figure 1).
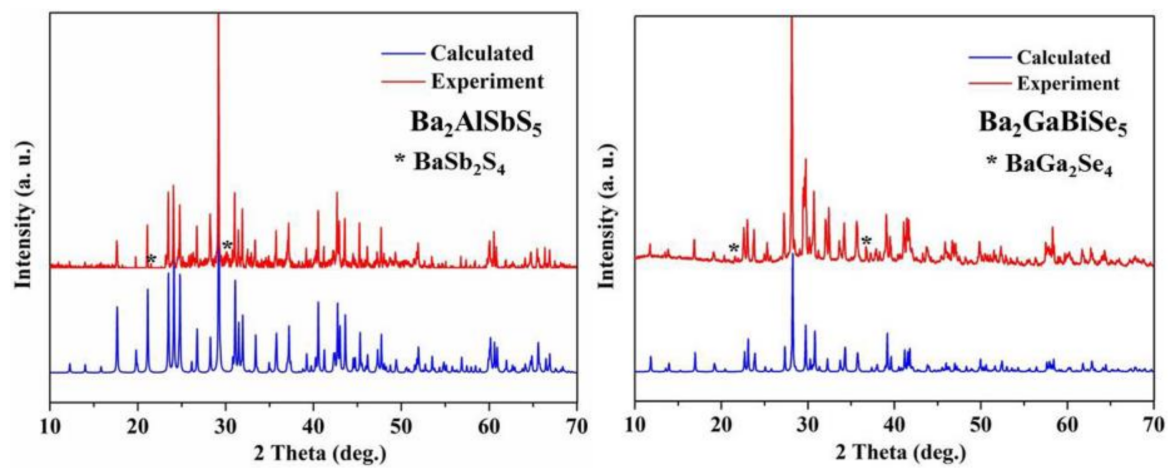

Figure 1. Powder XRD patterns of title compounds.

\subsection{UV-Vis-NIR Diffuse-Reflectance Spectroscopy}

Diffuse-reflectance spectra were measured by a Shimadzu SolidSpec-3700DUV spectrophotometer (Shimadzu Corporation, Beijing, China) in the wavelength range of $200-2600 \mathrm{~nm}$ at room temperature. The absorption spectra were converted from the reflection spectra via the Kubelka-Munk function.

\subsection{Raman Spectroscopy}

Hand-picked crystals were firstly put on an object slide, and then a LABRAM HR Evolution spectrometer (HORIBA Scientific, Beijing, China) equipped with a CCD detector by a $532 \mathrm{~nm}$ laser was used to record the Raman spectra. The integration time was set to be $5 \mathrm{~s}$. 


\subsection{Theoretical Calculation}

On the basis of ab initio calculation implemented in the CASTEP package (version 6.1), the density functional theory (DFT) was used to obtain electronic structures [27]. The Perdew-Burke-Ernzerhof (PBE) was used to calculate the exchange-correlation effects in the generalized gradient approximation (GGA) [28]. The following orbital electrons were regarded as valence electrons; Ba: $5 s^{2} 5 p^{6} 6 s^{2}$; Al: $3 s^{2} 3 p^{1}$, S: $3 s^{2} 3 p^{4}$; Se: $4 s^{2} 4 p^{4}$; Sb: $5 s^{2} 5 p^{3}$; Ga: $4 s^{2} 4 p^{1}$; Bi: $6 s^{2} 6 p^{3}$. The energy cutoff of the plane-wave basis set was $700.0 \mathrm{eV}$ within Normconserving pseudopotential (NCP), and the Monkhorst-Pack scheme $(3 \times 3 \times 4)$ for the Brillouin Zone was chosen [29,30]. As an important parameter for optical crystals, refractive index was also calculated. Owing to the discontinuity of exchange correlation energy, the experimental value is usually larger than that of calculated band gap. Thus, scissors operators are always used to make the conduction bands (CBs) agree with the experimental values [31].

\section{Results and Discussion}

\subsection{Crystal Structure}

The title compounds crystallize in the same orthorhombic space group Pnma, but there are obvious differences in their structures. As for $\mathrm{Ba}_{2} \mathrm{AlSbS}_{5}$, its asymmetrical unit is composed of one $\mathrm{Ba}$, one $\mathrm{Al}$, one $\mathrm{Sb}$, and four $\mathrm{S}$ atoms. As can be seen from its structure, the $\mathrm{Al}$ atoms are linked with four $\mathrm{S}$ atoms to form $\mathrm{AlS}_{4}$ tetrahedra with $d(\mathrm{Al}-\mathrm{S})=2.189(3)-2.2599(17) \AA$, and the $\mathrm{Sb}$ atoms connect with three $\mathrm{S}$ atoms to compose $\mathrm{SbS}_{3}$ units with $d(\mathrm{Sb}-\mathrm{S})=2.4294(19)-2.5191(13) \AA$. The above two units $\left(\mathrm{AlS}_{4}\right.$ and $\mathrm{SbS}_{3}$ ) interconnect with each other to form the isolated $\left[\mathrm{AlSbS}_{5}\right]^{4-}$ clusters (0D) (Figure 2a-c). The Ba atoms are connected with eight $\mathrm{S}$ atoms to form typical $\mathrm{BaS}_{8}$ dodecahedra. Additionally, the $\mathrm{BaS}_{8}$ units connect together to form the wavelike layers that can be clearly found along the $b$-axis (Figure 2e,f). Then, these layers further interconnect by sharing their corners or edges to form a 3D framework structure (Figure 2d). Thus, its whole structure can also be depicted as the interconnection of 0D $\left[\mathrm{AlSbS}_{5}\right]^{4-}$ clusters and $\mathrm{BaS}_{8}$ units.

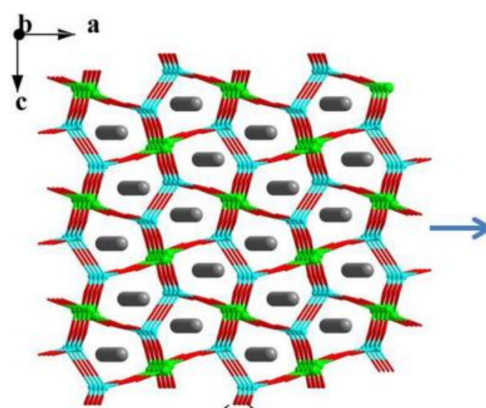

(a)

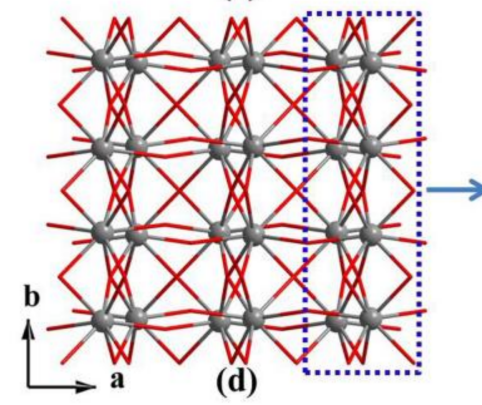

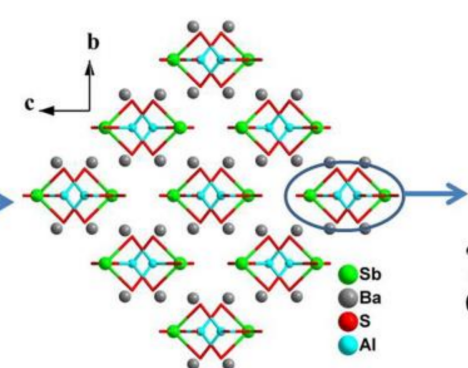

(b)

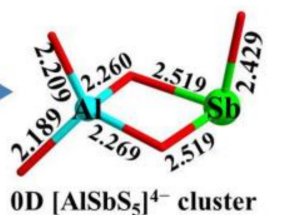

(c)

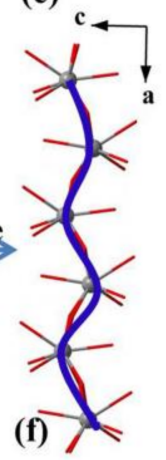

Figure 2. (a) Crystal structure of $\mathrm{Ba}_{2} \mathrm{AlSbS}_{5}$ with the Ba-S bonds omitted for clarity; (b) view of the crystal structure of $\mathrm{Ba}_{2} \mathrm{AlSbS}_{5}$ along the $a$-axis; (c) $0 \mathrm{D}\left[\mathrm{AlSbS}_{5}\right]^{4-}$ cluster; (d) 3D framework structure composed of $\mathrm{BaS}_{8}$ units; (e) one wavelike layer composed of $\mathrm{BaS}_{8}$ units located at the $b c$ plane; (f) view of wavelike layer along the $b$-axis. 
$\mathrm{Ba}_{2} \mathrm{GaBiSe}_{5}$ exhibits a different structure from $\mathrm{Ba}_{2} \mathrm{AlSbS}_{5}$, and it exhibits a 3D framework structure consisting of infinite $1 \mathrm{D} \infty\left[\mathrm{GaBiSe}_{5}\right]^{4-}$ chains with $d(\mathrm{Ga}-\mathrm{Se})=2.3409(18)-2.4304(13) \AA$ and $d(\mathrm{Bi}-\mathrm{Se})$ $=2.6517(14)-3.1918(11) \AA$ and Ba cations located between the chains for charge balance; in other

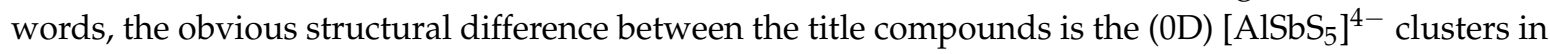
$\mathrm{Ba}_{2} \mathrm{AlSbS}_{5}$ versus $1 \mathrm{D} \infty\left[\mathrm{GaBiSe}_{5}\right]^{4-}$ chains in $\mathrm{Ba}_{2} \mathrm{GaBiSe}_{5}$ (Figure 3). Moreover, an overall literature investigation shows that dozens of quaternary compounds have been found in the $\mathrm{Ba}_{2} \mathrm{M}^{\mathrm{III}} \mathrm{M}^{\mathrm{III}} \mathrm{Q}_{5}\left(\mathrm{M}^{\mathrm{III}}\right.$ $=\mathrm{Al}, \mathrm{Ga}, \mathrm{In} ; \mathrm{M}^{\mathrm{III}}=\mathrm{As}, \mathrm{Sb}$, or $\mathrm{Bi} ; \mathrm{Q}=\mathrm{S}, \mathrm{Se}, \mathrm{Te}$ ) formula [17-21]. Detailed analysis on their structures shows that all of them crystallize in two different space groups: Pnma and $C m c 2_{1}$. The comparison of their structures shows that the interconnection of $\mathrm{M}^{\mathrm{III}} \mathrm{S}_{4}$ and $\mathrm{M}^{\mathrm{III}} \mathrm{S}_{n}(n=3,5,6)$ units can form three different structural types, including isolated $0 \mathrm{D}\left[\mathrm{M}^{\mathrm{III}} \mathrm{M}^{\mathrm{III}} \mathrm{Q}_{5}\right]$ cluster, single $\left[\mathrm{M}^{\mathrm{III}} \mathrm{Q}_{3}\right]$ chains and isolated $\left[\mathrm{M}^{\mathrm{III}} \mathrm{Q}_{4}\right]$ units, or $\left[\mathrm{M}^{\mathrm{III}} \mathrm{Q}_{3}\right]_{n}$ and $\left[\mathrm{M}^{\mathrm{III}} \mathrm{Q}_{3}\right]_{n}$ double chains, which may be induced by the flexible coordination and on-link modes of $\mathrm{M}^{\mathrm{III}}$ atoms (Table 2). Note that they are inclined to form $0 \mathrm{D}$ dimers, while $\mathrm{M}^{\mathrm{III}}$ and $\mathrm{M}^{\mathrm{III}}$ ' are smaller-sized atoms, such as $\mathrm{Al}$ and $\mathrm{Sb}$ or $\mathrm{Ga}$ and As atoms; otherwise, they tend to compose 1D chains due to the larger-sized atoms that exist in the structure, such as In, Bi or Te atoms. A topological approach has also been applied to better understand their structural differences, and the $\mathrm{BaS}_{8}$ units are simplified as the nodes. As a result, from Figure 4, it is clear that $\mathrm{BaS}_{8}$ units form a topological honeycomb-like tunnel framework in the Pnma space group, whereas they compose the topological layers in the $C m c 2_{1}$ space group.

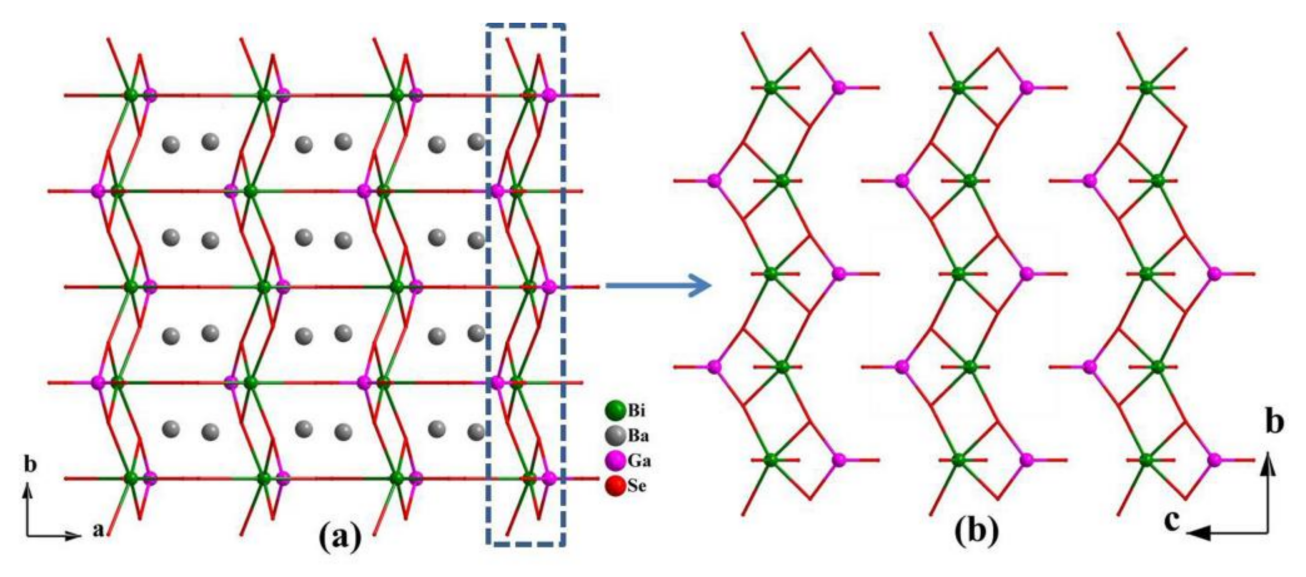

Figure 3. (a) View of the crystal structure of $\mathrm{Ba}_{2} \mathrm{GaBiSe}_{5}$ along the $c$-axis; (b) isolated 1D ${ }_{\infty}\left[\mathrm{GaBiSe}_{5}\right]^{4-}$ chains.

Table 2. Structural comparison among the series of $\mathrm{Ba}_{2} \mathrm{M}^{\mathrm{III}} \mathrm{M}^{\mathrm{III}}{ }^{\prime} \mathrm{Q}_{5}\left(\mathrm{M}^{\mathrm{III}}=\mathrm{Al}, \mathrm{Ga}\right.$, In; $\mathrm{M}^{\mathrm{III}}=\mathrm{As}, \mathrm{Sb}$, or $\mathrm{Bi} ; \mathrm{Q}=\mathrm{S}$, Se, $\mathrm{Te}$ ) compounds.

\begin{tabular}{|c|c|c|c|c|}
\hline Compounds & Crystal System & Space Group & Anion Connection Mode & Ref. \\
\hline $\mathrm{Ba}_{2} \mathrm{GaSbS}_{5}$ & orthorhombic & Pnma & ${ }_{\infty}\left[\mathrm{SbS}_{3}\right]_{n}$ chain and $\mathrm{GaS}_{4}$ & [20] \\
\hline $\mathrm{Ba}_{2} \mathrm{GaSbSe}_{5}$ & orthorhombic & Pnma & ${ }_{\infty}\left[\mathrm{SbSe}_{3}\right]_{n}$ chain and $\mathrm{GaSe}_{4}$ & [18] \\
\hline $\mathrm{Ba}_{2} \mathrm{GaSbTe}_{5}$ & orthorhombic & Pnma & ${ }_{\infty}\left[\mathrm{SbTe}_{3}\right]_{n}$ chain and $\mathrm{GaTe}_{4}$ & [18] \\
\hline $\mathrm{Ba}_{2} \mathrm{GaBiS}_{5}$ & orthorhombic & Pnma & ${ }_{\infty}\left[\mathrm{BiS}_{3}\right]_{n}$ chain and $\mathrm{GaS}_{4}$ & [21] \\
\hline $\mathrm{Ba}_{2} \mathrm{GaBiSe}_{5}$ & orthorhombic & Pnma & ${ }_{\infty}\left[\mathrm{BiSe}_{3}\right]_{n}$ chain and $\mathrm{GaSe}_{4}$ & [18], this work \\
\hline $\mathrm{Ba}_{2} \mathrm{GaBiTe}_{5}$ & orthorhombic & Pnma & ${ }_{\infty}\left[\mathrm{BiTe}_{3}\right]_{n}$ chain and $\mathrm{GaTe}_{4}$ & [18] \\
\hline $\mathrm{Ba}_{2} \mathrm{InSbTe}_{5}$ & orthorhombic & Pnma & ${ }_{\infty}\left[\mathrm{SbTe}_{3}\right]_{n}$ chain and $\operatorname{InTe}_{4}$ & [18] \\
\hline $\mathrm{Ba}_{2} \mathrm{InSbSe} \mathrm{S}_{5}$ & orthorhombic & $\mathrm{Cmc} 2_{1}$ & {$\left[\mathrm{InS}_{3}\right]_{n}$ and $\left[\mathrm{SbS}_{3}\right]_{n}$ chains } & [18] \\
\hline $\mathrm{Ba}_{2} \mathrm{InBiS}_{5}$ & orthorhombic & $\mathrm{Cmc}_{1}$ & {$\left[\mathrm{InS}_{3}\right]_{n}$ and $\left[\mathrm{BiS}_{3}\right]_{n}$ chains } & [21] \\
\hline $\mathrm{Ba}_{2} \mathrm{InBiSe}{ }_{5}$ & orthorhombic & $\mathrm{Cmc2} 2_{1}$ & {$\left[\mathrm{InSe}_{3}\right]_{n}$ and $\left[\mathrm{BiSe}_{3}\right]_{n}$ chains } & [19] \\
\hline $\mathrm{Ba}_{2} \mathrm{GaAsSe}_{5}$ & orthorhombic & Pnma & $0 \mathrm{D}\left[\mathrm{GaAsSe}_{5}\right]^{4-}$ cluster & [17] \\
\hline $\mathrm{Ba}_{2} \mathrm{AlSbS}_{5}$ & orthorhombic & Pnma & $0 \mathrm{D}\left[\mathrm{AlSbS}_{5}\right]^{4-}$ cluster & This work \\
\hline
\end{tabular}



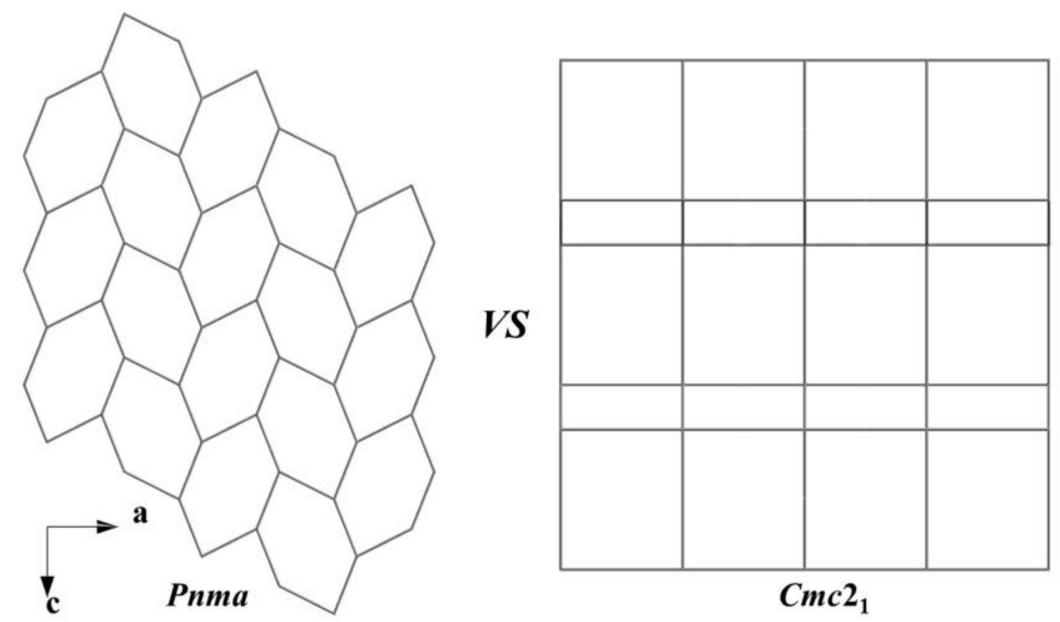

Figure 4. (a) Topological structure in Pnma space group with the $\mathrm{BaS}_{8}$ units regarded as the nodes; (b) topological structure in $C m c 2_{1}$ space group with $\mathrm{BaS}_{8}$ units regarded as the nodes.

\subsection{Optical Properties}

Diffuse-reflectance spectra of the title compounds were measured in the wavelength range of 200-2600 $\mathrm{nm}$ at room temperature (Figure 5). Through an absorption edge and the linear part of absorption plot, the band gaps of $\mathrm{Ba}_{2} \mathrm{AlSbS}_{5}$ and $\mathrm{Ba}_{2} \mathrm{GaBiSe}_{5}$ were deduced by a straightforward extrapolation method [32] as 2.57 and $2.14 \mathrm{eV}$, respectively, which are values much larger than those of a series of commercial IR materials, such as $\mathrm{ZnGeP}_{2}(1.65 \mathrm{eV})$ and $\mathrm{AgGaSe}_{2}(1.75 \mathrm{eV})[33,34]$. Moreover, we also measured their Raman spectra (Figure 6). Note that there were no obvious absorption bands above $400 \mathrm{~cm}^{-1}$ in $\mathrm{Ba}_{2} \mathrm{AlSbS}_{5}$ or $300 \mathrm{~cm}^{-1}$ in $\mathrm{Ba}_{2} \mathrm{GaBiSe}_{5}$, which shows that they may have wide IR transmission ranges. As for $\mathrm{Ba}_{2} \mathrm{AlSbS}_{5}$, the absorption bands above $200 \mathrm{~cm}^{-1}$, such as 242,304 , and $352 \mathrm{~cm}^{-1}$, can be can be assigned to the characteristic absorptions of the Al-S and Sb-S modes, which are similar to those of other related compounds, such as Al-S $\left(375 \mathrm{~cm}^{-1}\right)$ in $\mathrm{K}\left(\mathrm{AlS}_{2}\right)\left(\mathrm{GeS}_{2}\right)$ [35], $\mathrm{Sb}-\mathrm{S}\left(360,300,340\right.$, and $\left.270 \mathrm{~cm}^{-1}\right)$ in $\mathrm{A}_{2} \mathrm{Sb}_{2} \mathrm{Sn}_{3} \mathrm{~S}_{10}(\mathrm{~A}=\mathrm{K}, \mathrm{Rb}, \mathrm{Cs})$ [36]. Additionally, owing to the heavier Se atoms, the Bi-Se and Ga-Se vibrations occur at lower bands of 193 and $230 \mathrm{~cm}^{-1}$ in $\mathrm{Ba}_{2} \mathrm{GaBiSe}_{5}$, which are also similar to those in $\mathrm{Ba}_{4} \mathrm{CuGa}_{5} \mathrm{Se}_{12}$ (Ga-Se, $\left.185-262 \mathrm{~cm}^{-1}\right)$ [37] and $\left(\mathrm{Bi}_{4} \mathrm{Se}_{4}\right)\left[\mathrm{AlCl}_{4}\right]_{4}$ (Bi-Se, 189 and $183 \mathrm{~cm}^{-1}$ ) [38]. In addition, the absorption bands located at 70 and $98 \mathrm{~cm}^{-1}$ primarily correspond to the $\mathrm{Ba}-\mathrm{S}$ in the $\mathrm{Ba}_{2} \mathrm{AlSbS}_{5}$, and the bands at $63,83,95$, and $129 \mathrm{~cm}^{-1}$ correspond to Ba-Se vibration in $\mathrm{Ba}_{2} \mathrm{GaBiSe}_{5}$, and are similar to those in $\mathrm{Na}_{2} \mathrm{BaSnS}_{4}$ and $\mathrm{Na}_{2} \mathrm{BaSnSe}_{4}$ [6].

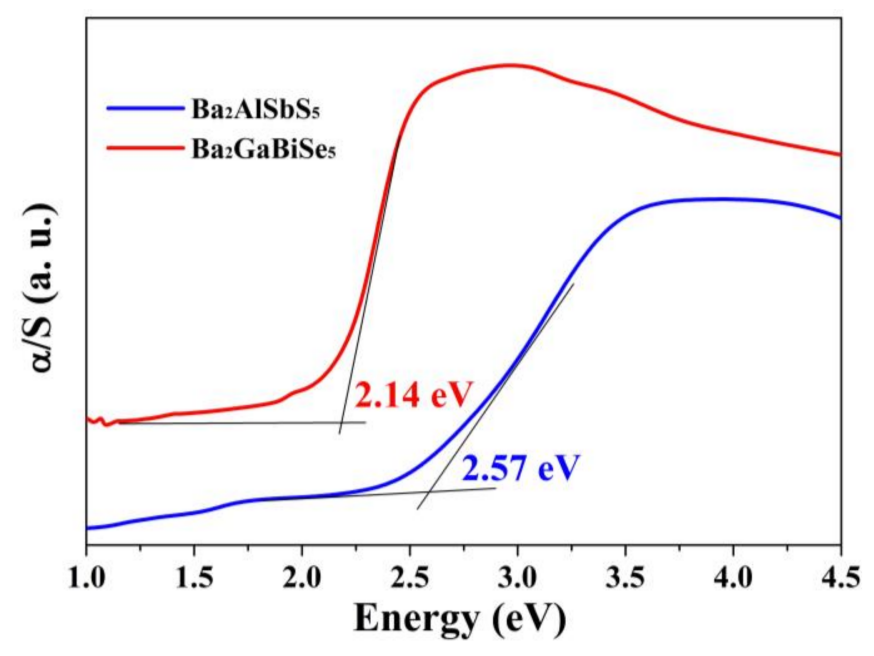

Figure 5. Experimental bandgaps of title compounds. 


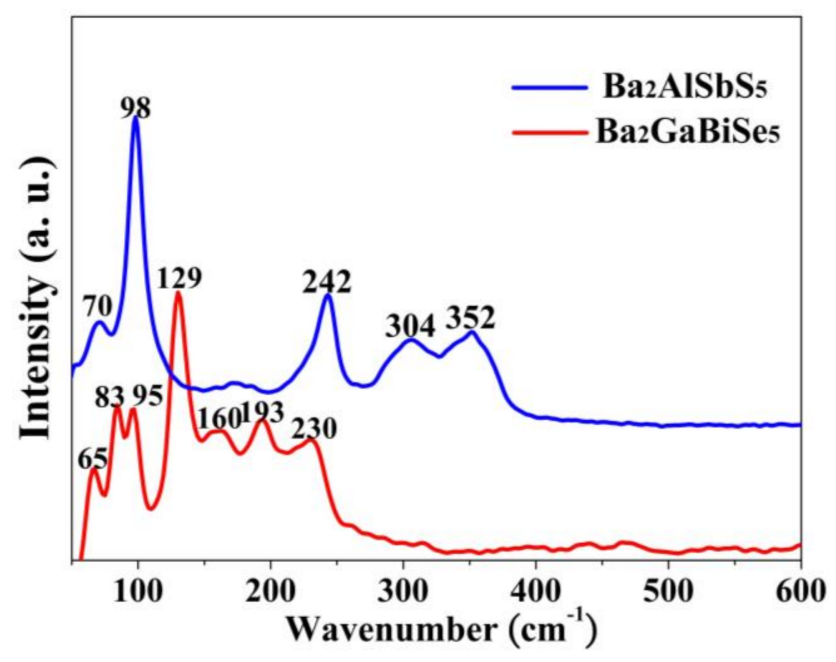

Figure 6. Raman spectra of title compounds.

\subsection{Theoretical Studies}

To further investigate the relationship between the structure and performance, the DFT method was chosen to complete the relative calculation. The calculated band structures for the title compounds are plotted in Figure 7, and show a pair of bonding and anti-bonding orbitals separated by gaps. $\mathrm{Ba}_{2} \mathrm{AlSbS}_{5}$ and $\mathrm{Ba}_{2} \mathrm{GaBiSe}_{5}$ are the indirect band-gap compounds with energy gaps of 2.40 and $1.89 \mathrm{eV}$, respectively.
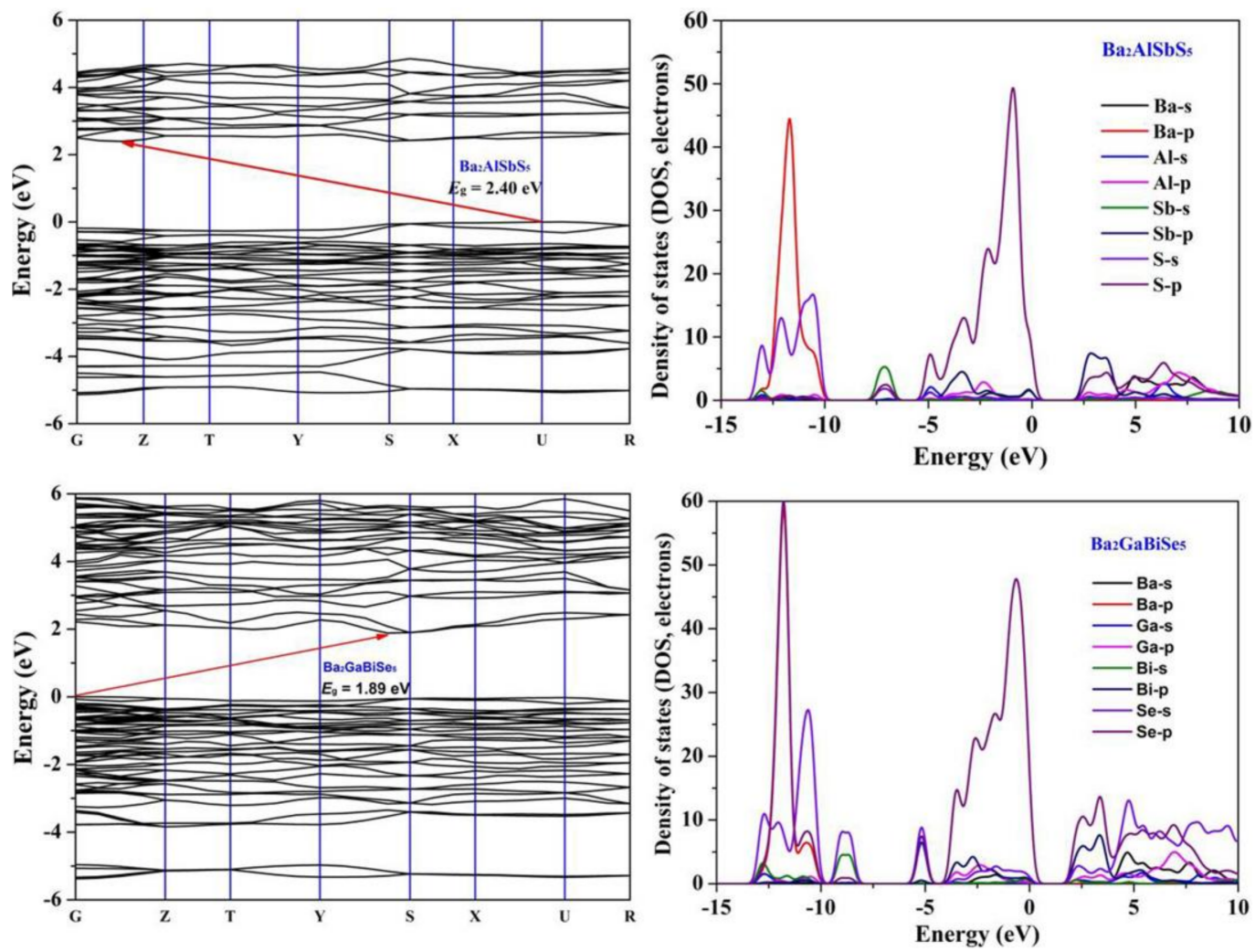

Figure 7. Band structures and PDOS diagrams of title compounds.

Herein, we focus our attention in the vicinity of Fermi level (FL), which counts for most of the bonding character, and is bound up with the optical parameters. For $\mathrm{Ba}_{2} \mathrm{AlSbS}_{5}$, the valence band (VB) 
near the FL can be divided into four regions: from -15 to $-10 \mathrm{eV}, \mathrm{S} 3 \mathrm{~s}$ states overlap completely with $\mathrm{Ba} 5 \mathrm{p}$, showing strong Ba-S covalent interactions. Bands in the region -7.5 to $-5.0 \mathrm{eV}$ mainly come from $\mathrm{Sb} 5 \mathrm{~s}$ and $\mathrm{S} 3 \mathrm{p}$ states, which shows some contributions to the Sb-S bonds. The upper part of VB, from $-5 \mathrm{eV}$ to FL, shows some hybridizations between Ba $5 \mathrm{~s}, \mathrm{~S} 3 \mathrm{p}, \mathrm{Al} 3 \mathrm{p}, \mathrm{Sb} 5 \mathrm{~s}, 5 \mathrm{p}$ orbitals, revealing a few chemical bonds between the Ba-S, Sb-S, and Al-S; but the top VB maximum is dominated by $\mathrm{S} 3 \mathrm{p}$ orbitals. In addition, for the CB bottom, it is dominated by the orbitals of all atoms, and the $\mathrm{S} 3 \mathrm{p}$ and $\mathrm{Sb} 5 \mathrm{p}$ orbitals determine the $\mathrm{CB}$ minimum of the $\mathrm{Ba}_{2} \mathrm{AlSbS}_{5}$ crystal. As for $\mathrm{Ba}_{2} \mathrm{GaBiSe}_{5}$, its PDOS diagram shows some differences with that of $\mathrm{Ba}_{2} \mathrm{AlSbS}_{5}$. The region between -15 and $-7.5 \mathrm{eV}$ mainly consists of $\mathrm{Ba} 5 \mathrm{p}$, Bi $6 \mathrm{~s}$ and Se $4 \mathrm{~s}$ orbitals, showing the obvious interactions of Ba-Se and Bi-Se bonds. The VB $(-6.0$ to $-4.0 \mathrm{eV})$ is mainly from the contributions of Bi $6 \mathrm{p}$ and Se $4 p$ states with some of the Ga $4 p$ orbitals, and for the bands in the region near the top of the VB (from -4.0 to FL), there is strong hybridization between the orbitals of Se $4 p$ and other atoms, which show obvious hybridization of Bi-Se and Ga-Se bonds. The orbitals of all atoms originate from 1.89 to $10 \mathrm{eV}$ of $\mathrm{CB}$, and the $\mathrm{Se} 4 \mathrm{p}$ orbitals dominate the $\mathrm{CB}$ minimum of the $\mathrm{Ba}_{2} \mathrm{GaBiSe}_{5}$ crystal. Therefore, the calculated PDOS shows that both the upper part of the VB and the bottom area of the CB are mainly dominated by Se $4 p$ and Bi 6 p orbitals. To sum up, optical absorption for the title compounds is mainly determined by the $\mathrm{M}^{\mathrm{III}} \mathrm{Q}_{\mathrm{n}}$ units. Additionally, based on the electronic structure, refractive indices are also obtained theoretically from the imaginary part of the dielectric function through a Kramers-Kronig transform [39]. The dispersion curves of the refractive indices calculated also display an obvious anisotropy, and their birefringences $(\Delta n)$ are about 0.13 for $\mathrm{Ba}_{2} \mathrm{GaBiSe}_{5}$ and 0.11 for $\mathrm{Ba}_{2} \mathrm{AlSbS}_{5}$, with wavelengths of about $1 \mu \mathrm{m}$. The large birefringence can be elucidated from their microscopic structural feature; the coplanar and aligned manners of the isolated (0D) $\left[\mathrm{AlSbS}_{5}\right]^{4-}$ clusters or $1 \mathrm{D} \infty\left[\mathrm{GaBiSe}_{5}\right]^{4-}$ chains are beneficial for their large birefringences. Therefore, the title compounds can be expected to be potential IR birefringent materials.

\section{Conclusions}

In this work, two metal chalcogenides, $\mathrm{Ba}_{2} \mathrm{AlSbS}_{5}$ and $\mathrm{Ba}_{2} \mathrm{GaBiSe}_{5}$, were successfully synthesized. Although they crystallize in the same Pnma space group, they exhibit obvious structural differences. In terms of their structures, $0 \mathrm{D}\left[\mathrm{AlSbS}_{5}\right]^{4-}$ clusters exist in the structure of $\mathrm{Ba}_{2} \mathrm{AlSbS}_{5}$, whereas $\mathrm{Ba}_{2} \mathrm{GaBiSe}_{5}$ has $1 \mathrm{D}{ }_{\infty}\left[\mathrm{GaBiSe}_{5}\right]^{4-}$ chains. After the systematic investigation of the series of $\mathrm{Ba}_{2} \mathrm{M}^{\mathrm{III}} \mathrm{M}^{\mathrm{III}} \mathrm{Q}_{5}\left(\mathrm{M}^{\mathrm{III}}=\right.$ $\left.\mathrm{Al}, \mathrm{Ga}, \mathrm{In} ; \mathrm{M}^{\mathrm{III} \prime}=\mathrm{As}, \mathrm{Sb}, \mathrm{Bi} ; \mathrm{Q}=\mathrm{S}, \mathrm{Se}, \mathrm{Te}\right)$ compounds, the interconnection of $\mathrm{M}^{\mathrm{III}} \mathrm{S}_{4}$ and $\mathrm{M}^{\mathrm{III}} \mathrm{S}_{n}(n=3$, $5,6)$ units can form three different structural types, including $0 \mathrm{D}\left[\mathrm{M}^{\mathrm{III}} \mathrm{M}^{\mathrm{III}} \mathrm{Q}_{5}\right]$ cluster, single $\left[\mathrm{M}^{\mathrm{III}} \mathrm{Q}_{3}\right]$ chains and isolated $\left[\mathrm{M}^{\mathrm{III}} \mathrm{Q}_{4}\right]$ units, and $\left[\mathrm{M}^{\mathrm{III}} \mathrm{Q}_{3}\right]_{n}$ and $\left[\mathrm{M}^{\mathrm{III}} \mathrm{Q}_{3}\right]_{n}$ double chains, which may be induced by the coordination and on-link modes of $\mathrm{M}^{\mathrm{III}}$ ' atoms. Their bandgaps are about $2.57 \mathrm{eV}$ for $\mathrm{Ba}_{2} \mathrm{AlSbS}_{5}$ and $2.14 \mathrm{eV}$ for $\mathrm{Ba}_{2} \mathrm{GaBiSe}_{5}$, respectively. Moreover, the title compounds exhibit larger birefringences $(\Delta n>0.10)$ and have potential as IR birefringent materials.

Supplementary Materials: The following are available online at http:/ /www.mdpi.com/2073-4352/8/4/165/s1. Cifs and checkcifs for title compounds.

Acknowledgments: This work was supported by the National Natural Science Foundation of China (Grant No. 21763026), Scientific Research Program of the Higher Education Institution of Xinjiang (Grant No. XJEDU2016S063), Ten Thousand People Plan Backup Project (Grant No. QN2016YX0340), and Xinjiang Key Laboratory of Electronic Information Materials and Devices (Grant No. 2017D04029).

Author Contributions: Xiaowen Wu designed this study and wrote the manuscript. Xiaofeng Gu prepared the crystals. Hui Pan analyzed the crystal structures. Yi Hu carried out the properties characterization work. Kui Wu conceived and coordinated the project.

Conflicts of Interest: The authors declare no conflict of interest.

\section{References}

1. Kwasi, M.; Ibers, J.A. Rare-earth transition-metal chalcogenides. Chem. Rev. 2002, 102, 1929-1952. 
2. Chung, I.; Kanatzidis, M.G. Metal chalcogenides: A rich source of nonlinear optical materials. Chem. Mater. 2014, 26, 849-869. [CrossRef]

3. Liang, F.; Kang, L.; Lin, Z.S.; Wu, Y.C.; Chen, C.T. Analysis and prediction of Mid-ir nonlinear optical metal sulfides with diamond-like structures. Coord. Chem. Rev. 2017, 333, 57-70. [CrossRef]

4. Guo, S.P.; Chi, Y.; Guo, G.C. Recent achievements on middle and far-infrared second-order nonlinear optical materials. Coord. Chem. Rev. 2017, 335, 44-57. [CrossRef]

5. Wu, K.; Pan, S.L. $\mathrm{Li}_{2} \mathrm{HgMS}_{4}(\mathrm{M}=\mathrm{Si}, \mathrm{Ge}, \mathrm{Sn})$ : New quaternary diamond-like semiconductors for infrared laser frequency conversion. Crystals 2017, 7, 107. [CrossRef]

6. Wu, K.; Yang, Z.H.; Pan, S.L. $\mathrm{Na}_{2} \mathrm{BaMQ}_{4}(\mathrm{M}=\mathrm{Ge}, \mathrm{Sn} ; \mathrm{Q}=\mathrm{S}$, Se): Infrared nonlinear optical materials with excellent performances and that undergo structural transformations. Angew. Chem. Int. Ed. 2016, 55, 6713-6715. [CrossRef] [PubMed]

7. Lin, H.; Chen, L.; Yu, J.S.; Chen, H.; Wu, L.M. Infrared SHG materials $\mathrm{CsM}_{3} \mathrm{Se}_{6}(\mathrm{M}=\mathrm{Ga} / \mathrm{Sn}$, In/Sn): Phase matchability controlled by dipole moment of the asymmetric building unit. Chem. Mater. 2017, 29, 499-503. [CrossRef]

8. $\quad$ Luo, Z.Z.; Lin, C.S.; Cui, H.H.; Zhang, W.L.; Zhang, H.; He, Z.Z.; Cheng, W.D. SHG materials $\mathrm{SnGa}_{4} \mathrm{Q}_{7}$ $(\mathrm{Q}=\mathrm{S}, \mathrm{Se})$ appearing with large conversion efficiencies, high damage thresholds, and wide transparencies in the mid-infrared region. Chem. Mater. 2014, 26, 2743-2749. [CrossRef]

9. Liang, F.; Kang, L.; Lin, Z.S.; Wu, Y.C. Mid-infrared nonlinear optical materials based on metal chalcogenides: Structure-property relationship. Cryst. Growth Des. 2017, 17, 2254-2289. [CrossRef]

10. Brant, J.A.; Clark, D.J.; Kim, Y.S.; Jang, J.I.; Zhang, J.H.; Aitken, J.A. $\mathrm{Li}_{2} \mathrm{CdGeS}_{4}$, a diamond-like semiconductor with strong second-order optical nonlinearity in the infrared and exceptional laser damage threshold. Chem. Mater. 2014, 26, 3045-3048. [CrossRef]

11. Xia, Z.G.; Poeppelmeier, K.R. Chemistry-inspired adaptable framework structures. Acc. Chem. Res. 2017, 50, 1222-1230. [CrossRef] [PubMed]

12. Ok, K.M. Toward the rational design of novel noncentrosymmetric materials: Factors influencing the framework structures. Acc. Chem. Res. 2016, 49, 2774-2785. [CrossRef] [PubMed]

13. Bera, T.K.; Jang, J.I.; Ketterson, J.B.; Kanatzidis, M.G. strong second harmonic generation from the tantalum thioarsenates $\mathrm{A}_{3} \mathrm{Ta}_{2} \mathrm{AsS}_{11}(\mathrm{~A}=\mathrm{K}$ and Rb). J. Am. Chem. Soc. 2009, 131, 75-77. [CrossRef] [PubMed]

14. Chen, M.C.; Li, L.H.; Chen, Y.B.; Chen, L. In-phase alignments of asymmetric building units in $\mathrm{Ln}_{4} \mathrm{GaSbS}_{9}$ $(\mathrm{Ln}=\mathrm{Pr}, \mathrm{Nd}, \mathrm{Sm}, \mathrm{Gd}-\mathrm{Ho})$ and their strong nonlinear optical responses in middle IR. J. Am. Chem. Soc. 2011, 133, 4617-4624. [CrossRef] [PubMed]

15. Bera, T.K.; Jang, J.I.; Song, J.H.; Malliakas, C.D.; Freeman, A.J.; Ketterson, J.B.; Kanatzidis, M.G. Soluble semiconductors $\mathrm{AAsSe}_{2}(\mathrm{~A}=\mathrm{Li}, \mathrm{Na})$ with a direct-band-gap and strong second harmonic generation: A combined experimental and theoretical study. J. Am. Chem. Soc. 2010, 132, 3484-3495. [CrossRef] [PubMed]

16. Zhou, J. Synthesis of heterometallic chalcogenides containing lanthanide and group 13-15 metal elements. Coord. Chem. Rev. 2016, 315, 112-134. [CrossRef]

17. Li, C.; Li, X.S.; Huang, H.W.; Yao, J.Y.; Wu, Y.C. Ba ${ }_{2} \mathrm{AsGaSe}_{5}$ : A new quaternary selenide with the novel $\left[\mathrm{AsGaSe}_{5}\right]^{4-}$ cluster and interesting photocatalytic properties. Inorg. Chem. 2015, 54, 9785-9789. [CrossRef] [PubMed]

18. Hao, W.Y.; Mei, D.J.; Yin, W.L.; Feng, K.; Yao, J.Y.; Wu, Y.C. Synthesis, structural characterization and optical properties of new compounds: Centrosymmetric $\mathrm{Ba}_{2} \mathrm{GaMQ}_{5}(\mathrm{M}=\mathrm{Sb}, \mathrm{Bi} ; \mathrm{Q}=\mathrm{Se}, \mathrm{Te}), \mathrm{Ba}_{2} \mathrm{InSbTe}_{5}$ and noncentrosymmetric $\mathrm{Ba}_{2} \mathrm{InSbSe}_{5}$. J. Solid State Chem. 2013, 198, 81-86. [CrossRef]

19. Lin, C.S.; Luo, Z.Z.; Cheng, W.D.; Zhang, H.; Zhang, W.L. Design of SHG materials with mid-infrared transparency based on genetic engineering for $\mathrm{Ba}_{2} \mathrm{BiInA}_{5}(\mathrm{~A}=\mathrm{Se}, \mathrm{Te})$. J. Mater. Chem. 2012, 22, 21713-21719. [CrossRef]

20. Geng, L.; Zhang, H.; Cheng, W.D. $\mathrm{Ba}_{2} \mathrm{SbGaS}_{5}$ : Solid-state synthesis, crystal and electronic structures, and property characterization. Chin. J. Struct. Chem. 2013, 32, 538-544.

21. Geng, L.; Cheng, W.D.; Lin, C.S.; Zhang, W.L.; Zhang, H.; He, Z.Z. Syntheses and characterization of new mid-infrared transparency compounds: Centric $\mathrm{Ba}_{2} \mathrm{BiGaS}_{5}$ and acentric $\mathrm{Ba}_{2} \mathrm{BiInS}_{5}$. Inorg. Chem. 2011, 50, 5679-5686. [CrossRef] [PubMed]

22. Iordanidis, L.; Brazis, P.W.; Kyratsi, T.; Ireland, J.; Lane, M.; Kannewurf, C.R.; Chen, W.; Dyck, J.S.; Uher, C.; Ghelani, N.A.; et al. $\mathrm{A}_{2} \mathrm{Bi}_{8} \mathrm{Se}_{13}(\mathrm{~A}=\mathrm{Rb}, \mathrm{Cs}), \mathrm{CsBi}_{3.67} \mathrm{Se}_{6}$, and $\mathrm{BaBi}_{2} \mathrm{Se}_{4}$ : New ternary semiconducting bismuth selenides. Chem. Mater. 2001, 13, 622-633. [CrossRef] 
23. Chung, D.Y.; Jobic, S.; Hogan, T.; Kannewurf, C.R.; Brec, R.; Rouxel, R.; Kanatzidis, M.G. Oligomerization versus polymerization of texn- in the polytelluride compound babite 3 . Structural characterization, electronic structure, and thermoelectric properties. J. Am. Chem. Soc. 1997, 119, 2505-2515. [CrossRef]

24. Kim, J.H.; Chung, D.Y.; Bilc, D.; Loo, S.; Short, J.; Mahanti, S.D.; Hogan, T.; Kanatzidis, M.G. Crystal growth, thermoelectric properties, and electronic structure of $\mathrm{AgBi}_{3} \mathrm{~S}_{5}$ and $\mathrm{AgSb}_{\mathrm{x}} \mathrm{Bi}_{3-\mathrm{x}} \mathrm{S}_{5}(\mathrm{x}=0.3)$. Chem. Mater. 2005, 17, 3606-3614. [CrossRef]

25. Sheldrick, G.M. Shelxtl; Version 6.14; Bruker Analytical X-Ray Instruments, Inc.: Madison, WI, USA, 2008.

26. Spek, A.L. Single-crystal structure validation with the program platon. J. Appl. Crystallogr. 2003, 36, 7-13. [CrossRef]

27. Clark, S.J.; Segall, M.D.; Pickard, C.J.; Hasnip, P.J.; Probert, M.J.; Refson, K.; Payne, M.C. First principles methods using castep. Z. Kristallogr. Cryst. Mater. 2005, 220, 567-570. [CrossRef]

28. Perdew, J.P.; Burke, K.; Ernzerhof, M. Generalized gradient approximation made simple. Phys. Rev. Lett. 1996, 77, 3865-3870. [CrossRef] [PubMed]

29. Rappe, A.M.; Rabe, K.M.; Kaxiras, E.; Joannopoulos, J.D. Optimized pseudopotentials. Phys. Rev. B 1990, 41, 1227-1230. [CrossRef]

30. Lin, J.S.; Qteish, A.; Payne, M.C.; Heine, V. Optimized and transferable non-local separable pseudopotentials. Phys. Rev. B 1993, 47, 4174-4178. [CrossRef]

31. Godby, R.W.; Schluter, M.; Sham, L.J. Self-energy operators and exchange-correlation potentials in semiconductors. Phys. Rev. B 1988, 37, 10159-10175. [CrossRef]

32. Schevciw, O.; White, W.B. The optical absorption edge of rare earth sesquisulfides and alkaline earth-rare earth sulfides. Mater. Res. Bull. 1983, 18, 1059-1068. [CrossRef]

33. Boyd, G.D.; Storz, F.G.; McFee, J.H.; Kasper, H.M. Linear and nonlinear optical properties of some ternary selenides. IEEE J. Quantum Electron. 1972, 8, 900-908. [CrossRef]

34. Boyd, G.D.; Buehler, E.; Storz, F.G. Linear and nonlinear optical properties of $\mathrm{ZnGeP}_{2}$ and CdSe. Appl. Phys. Lett. 1971, 18, 301-304. [CrossRef]

35. Al-Bloushi, M.; Davaasuren, B.; Emwas, A.H.; Rothenberger, A. Synthesis and characterization of the quaternary thioaluminogermanates $\mathrm{A}\left(\mathrm{AlS}_{2}\right)\left(\mathrm{GeS}_{2}\right)(\mathrm{A}=\mathrm{Na}, \mathrm{K})$. Z. Anorg. Allg. Chem. 2015, 641, 1352-1356. [CrossRef]

36. Yohannan, J.P.; Vidyasagar, K. Syntheses and characterization of one-dimensional alkali metal antimony (III) thiostannates (IV), $\mathrm{A}_{2} \mathrm{Sb}_{2} \mathrm{Sn}_{3} \mathrm{~S}_{10}(\mathrm{~A}=\mathrm{K}, \mathrm{Rb}, \mathrm{Cs})$. J. Solid State Chem. 2015, 221, 426-432. [CrossRef]

37. Kuo, S.M.; Chang, Y.M.; Chung, I.; Jang, J.I.; Her, B.H.; Yang, S.H.; Ketterson, J.B.; Kanatzidis, M.G.; Hsu, K.F. New metal chalcogenides $\mathrm{Ba}_{4} \mathrm{CuGa}_{5} \mathrm{Q}_{12}(\mathrm{Q}=\mathrm{S}$, Se) displaying strong infrared nonlinear optical response. Chem. Mater. 2013, 25, 2427-2433. [CrossRef]

38. Beck, J.; Schlüter, S.; Zotov, N. The cube-shaped main group element clusters $\left(\mathrm{Bi}_{4} \mathrm{~S}_{4}\right)^{4+}$ and $\left(\mathrm{Bi}_{4} \mathrm{Se}_{4}\right)^{4+}$-Synthesis from chloroaluminate melts, crystal structures and vibrational spectra. Z. Anorg. Allg. Chem. 2004, 630, 2512-2519. [CrossRef]

39. Wooten, F. Optical Properties of Solid; Academic Press: New York, NY, USA, 1972.

(C) 2018 by the authors. Licensee MDPI, Basel, Switzerland. This article is an open access article distributed under the terms and conditions of the Creative Commons Attribution (CC BY) license (http:// creativecommons.org/licenses/by/4.0/). 